in specialist books, but there is much to be said for a concise summary of the principles of a technique together with some carefully selected examples of its use. Dr Andrews is not content simply to describe a technique, but goes to considerable lengths to provide compact quantitative treatments of the various physical principles involved, in a way which will enlighten the serious student, and refresh the memories of established scientists who may have long taken the underlying principles for granted.

The first volume is rather dominated by the subject of $\mathrm{X}$-ray and electron diffraction and associated techniques, which together with an introductory outline of erystallographic principles takes up two thirds of the volume. This perhaps refiects the author's own research interests, but it is appropriate that methods which have been so effective in physical metallurgy should receive substantial emphasis. It does however mean that more recently developed techniques such as field emission and field ion microscopy receive much less attention than they deserve. Other subjects dealt with in this volume include thermal methods and solidification techniques. The former deserve a place in any book of this type, for although they reach back almost to the genesis of the subject, in their modern forms they are still extremely valuable methods of investigation. The chapter on solidification techniques is rather brief and apart from a useful treatment on zone refining does little to stress the importance of this stage in alloy preparation.

The first part of Volume 2 deals with both optical and electron microscopy. It is refreshing to see that the rapidly growing subject of quantitative metallography receives due attention, while there is a fifty-page review of electron microscopy which provides clear simple treatments of image formation and the basic contrast effects. The latter half of this volume is likely to be particularly useful, as it deals with several topics about which rather less has been written recently. In particular the chapter on the determination of internal stresses is an excellent review which again reflects a special interest of the author, who has taken pains to spell out the underlying principles of stresses on macro and micro scales, and also around dislocations. The other chapters in this volume are concerned with electrical and magnetic methods, and with internal friction techniques. The latter subject has not received much attention recently, so a compact review of this type is likely to prove most valuable.

In summary these two volumes provide a most useful survey of a number of physical techniques important in metallurgical research. The able combination of basic theory with practical application of the techniques should appeal to a wide spectrum of readers.

R. W. K. Honeycombe

\section{Phoenix palaeontology}

Evolutionary Paleoecology of the $\mathrm{Ma}$ rine Biosphere. By $\mathrm{J}$. W. Valentine. Pp. xv + 511. (Prentice-Hall: Englewood Cliffs, NJ, October 1973.) \$6.95.

The past few years have witnessed striking advances in the application of modern concepts of ecology, evolutionary biology and plate tectonics to achieve an improved understanding of the fossil record, and it is appropriate that the first comprehensive review of this revitalised palaeontology should be written by one of the leading workers in this sphere. In the early part of his book Valentine gives a useful survey of evolutionary and ecological theory and of the principal physical parameters of the marine environment. He goes on in the more substantial part of the book to treat marine animals in terms of a hierarchical system. Successive chapters deal with the mode of life and functional morphology of individual organisms, populations, communities, faunal provinces and the marine biosphere, ending with general interpretation of the evolutionary history of this biosphere from the Precambrian to the present. Each level in the hierarchy can be viewed as a sort of 'black box', with its own intrinsic patterns of organisation which can often be studied without reference to lower or higher levels. Thus when dealing with patterns of community organisation one does not necessarily have to be preoccupied unduly with the relationship of form and function for particular phenotypes, and so on.

One of the most impressive features of this fine book is the overall conceptual framework created, which breaks away refreshingly from the somewhat stultifying preoccupation with particular taxa, with no particular scientific goal in mind, which has characterised so much palaeontology in the past. Another is the erection of a series of testable models. It is not that detail is ignored, far from it, but it is subsumed into a more general system so that one can evaluate more readily the relevance of making certain types of observation as a means of testing particular hypotheses.

Valentine's own research has been mainly concerned with the higher organisational levels and his important views on such matters as the environmental control on provinciality, diversity changes, mass extinctions and the evolution of basic morphological structures through geological time are nat- urally given a good airing. The presentation of these views is, however, not dogmatic and one does not have to agree with all he says to accept that he is laying emphasis on the sorts of problems to which the palaeontological community should address itself increasingly in the future. The writing style is generally clear and where new jargon is introduced it is well defined. The production is generally good, and illustrations abundant, though the number of typographical errors is large. The book can be used with profit in advanced undergraduate courses and deserves to be read by all who want to learn more about the new palaeontology.

A. Hallam

\section{Biological names}

Biolos,ical Nomenclature. By Charles Jeffrey. Pp. ix +69. (Arnold: London, October, 1973.) $£ 2$ boards; $£ 1$ paper.

"What! Is it possible? Not to know the principles of nomenclature? Of what can your teachers have been thinking?"

Older biologists should no longer need thus to paraphrase Rob Roy. Dr Jeffrey's book shows clearly how far there is a simple common basis to the various international codes of biological nomenclature, and how they differ in expression.

Dr Jeffrey is a botanist. A zoologist may find points to criticise, of which I mention two. First, it is not true that publication is the process of making a zoological name available (page 64) (see chapter 4 of the zoological code). Second, the notion of the "nominal taxon" is misrepresented. It is not enough to say (page 63) that it is the taxon that bears a given name: it is the taxon, as objectively defined by its type, to which a given name applies. Botanists speak of "the type of a name", which is to imply, in cases of homonymy, that one concept can have two or more different objective bases, which is a nonsense. The name is not the same thing as the concept it denotes. To $\mathrm{Dr}$ Jeffrey "The type of a name ... has no significance for classífication" (page 18). To a zoologist, the nominal taxon is the concept that is common to all notions of the taxon. As such, it provides the essential link between classification and nomenclature and is a notion of great practical value.

Nevertheless, biologists at all levels of experience should study this book. Dr Jeffrey and the Systematics Association have rendered a major service to all biologists whose work calls for some understanding of the basic principles of nomenclature.

R. V. Melville 